\title{
A cartilage tissue engineering approach combining starch-polycaprolactone fibre mesh scaffolds with bovine articular chondrocytes
}

\author{
J. T. Oliveira $\cdot$ A. Crawford $\cdot$ J. M. Mundy · \\ A. R. Moreira · M. E. Gomes · P. V. Hatton · R. L. Reis
}

Received: 6 July 2006 / Accepted: 25 September 2006

(C) Springer Science + Business Media, LLC 2007

\begin{abstract}
In the present work we originally tested the suitability of corn starch-polycaprolactone (SPCL) scaffolds for pursuing a cartilage tissue engineering approach. Bovine articular chondrocytes were seeded on SPCL scaffolds under dynamic conditions using spinner flasks (total of 4 scaffolds per spinner flask using cell suspensions of $0.5 \times 10^{6}$ cells $/ \mathrm{ml}$ ) and cultured under orbital agitation for a total of 6 weeks. Poly(glycolic acid) (PGA) non-woven scaffolds and bovine native articular cartilage were used as standard controls for the conducted experiments. PGA is a kind of standard in tissue engineering approaches and it was used as a control in that sense. The tissue engineered constructs were characterized at different time periods by scanning electron microscopy (SEM), hematoxylin-eosin (H\&E) and toluidine blue stainings, immunolocalisation of collagen types I and II, and dimethylmethylene blue (DMB) assay for glycosaminoglycans (GAG) quantification assay. SEM results for SPCL constructs showed that the chondrocytes presented normal morphological features, with extensive cells presence at the surface of the support structures, and penetrating the scaffolds pores. These observations were further corroborated by H\&E staining. Toluidine blue and immunohistochemistry exhibited extracellular matrix deposition throughout the 3D
\end{abstract}

J. T. Oliveira $(\bowtie) \cdot$ A. R. Moreira $\cdot$ M. E. Gomes $\cdot$ R. L. Reis 3B's Research Group-Biomaterials, Biodegradables, and Biomimetics, University of Minho, Campus de Gualtar, 4710-057 Braga, Portugal

e-mail: joao.oliveira@dep.uminho.pt

J. T. Oliveira · A. R. Moreira · M. E. Gomes $\cdot$ R. L. Reis Department of Polymer Engineering, University of Minho, Guimarães, Portugal

A. Crawford · J. M. Mundy · P. V. Hatton Centre for Biomaterials and Tissue Engineering, School of Clinical Dentistry, University of Sheffield, Sheffield, UK structure. Glycosaminoglycans, and collagen types I and II were detected. However, stronger staining for collagen type II was observed when compared to collagen type I. The PGA constructs presented similar features to SPCL at the end of the 6 weeks. PGA constructs exhibited higher amounts of matrix glycosaminoglycans when compared to the SPCL scaffolds. However, we also observed a lack of tissue in the central area of the PGA scaffolds. Reasons for these occurrences may include inefficient cells penetration, necrosis due to high cell densities, or necrosis related with acidic by-products degradation. Such situation was not detected in the SPCL scaffolds, indicating the much better biocompatibility of the starch based scaffolds.

\section{Introduction}

Articular cartilage is an avascular supporting connective tissue, exhibiting a low metabolic rate and a low regenerative potential [1-3]. The ability of articular cartilage to function as a weight bearing tissue is dependent on the appropriate structural organisation and biochemical composition of the extracellular matrix, the two major components of which are collagen type II and proteoglycan [3-5]. The collagen is responsible for the tensile properties and the proteoglycans for compression resistance [6, 7].

Articular cartilage is responsible for the correct functioning of the articulating skeleton, creating smooth gliding areas in the terminal parts of bones responsible for shock absorbance, load bearing and reduction of surface friction [8]. Trauma, aging related degeneration such as osteoarthritis, or developmental disorders, can result in pain and disability. Adult cartilage has limited self repair capacity and even when some regeneration exists, fibrocartilage-like tissue is frequently formed in the defect $[5,9,10]$. This type of 
cartilage possesses lower mechanical properties when compared to articular cartilage, compromising its functional role in weight bearing.

Different strategies have been put forward to treat articular cartilage lesions. One common treatment in elderly patients is prosthetic joint replacement. Although successful, this invasive approach does not always provide long-term joint functionality due to loosening or limited life span of the prostheses [11]. Surgical procedures like osteotomy, perichondral grafting, interposition arthroplasty, and drilling, have been performed though the outcomes may be limited [8, 12]. Several and different tissue engineering approaches are being conducted to regenerate cartilage, most of them based on seeding cells in a polymeric matrix. The materials used to serve as cells supports can be processed in various ways, including extrusion and moulding, among others. These procedures can generate porous structures (scaffolds) of different shapes and sizes, e.g. fibres with more regular or irregular surfaces with varying diameters, membranes, and others [13]. The materials used for tissue engineering may be broadly divided into synthetic and natural materials. Starch is a natural polymer made of a combination of two polymeric carbohydrates, amylose and amylopectin [14, 15]. It has been put forward as a cell support material in combination with synthetic polymers such as polycaprolactone (PCL), polylactic acid (PLA), ethyl vinyl alcohol (EVOH), cellulose acetate (CA) giving rise to a blend that is expected to deliver better results. Several studies have been conducted with these materials, mainly in bone tissue engineering [16-19]. Polycaprolactone (PCL) is a synthetic semicrystalline biodegrabable polymer belonging to the family of poly- $\alpha$-hydroxyl polyesters, that has also been used for such approaches [20,21].

In this study, we have shown for the first time, the suitability of starch-polycaprolactone (SPCL) scaffolds for pursuing a cartilage tissue engineering approach. Bovine articular chondrocytes were cultured on starch-polycaprolactone fibre scaffolds for periods of up to 6 weeks. Cells were initially seeded using spinner flask bioreactors and then cultured in an orbital shaker for the remaining time periods. The scaffold fibre structure allowed the cells to efficiently penetrate the bulk besides the colonization of the most outer parts. We have analysed cell distribution, morphology and extracellular matrix components deposition during the course of the experiments, and the results obtained are encouraging in indicating a utility of SPCL scaffolds for a tissue engineering cartilage regeneration strategy.

\section{Materials and methods}

\subsection{Scaffolds production}

The methodology used to produce the scaffolds was melt spinning (to obtain the polymeric fibres) followed by fibre bonding [22]. This processing technique involves fibre packing in an appropriate mould, with posterior heating below the melting temperature $(\mathrm{Tm})$ for a determined residence period that will allow the fibres to form a stable fibre mesh structure. The material used was a 30/70\% (wt) blend of corn starch with polycaprolactone (SPCL). These scaffolds have already been shown previously to be suitable for conducting a bone tissue engineering approach $[17,23]$. The scaffolds produced were cut in a cylindrical shape, with dimensions of $7 \mathrm{~mm}$ diameter $\times 3 \mathrm{~mm}$ thickness. The porosity of the scaffolds was determined by microcomputerized tomography $(\mu \mathrm{CT})$ (ScanCo Medical $\mu$ CT 80, Bassersdorf, Switzerland) at a resolution of $10 \mathrm{~mm}$, and using at least 3 samples.

For comparison purposes, it should be stated that the PGA scaffolds dimensions were the same as those of SPCL. Both types of scaffolds were cut using a borer.

\subsection{Isolation and expansion of bovine articular chondrocytes}

Full thickness hyaline cartilage was harvested from bovine metacarpophalangeal joint of adult animals (18-24 months) within $4 \mathrm{~h}$ of slaughter. Chondrocytes were isolated by sequential enzymatic digestion as described previously [24]. The isolated cells were ressuspended in expansion medium (Dulbecco's Modified Eagle's Medium (Sigma Co.), containing $10 \mathrm{mM}$ HEPES buffer pH 7.4 (Sigma Co.), 10000 units/ml penicillin/10000 $\mu \mathrm{g} / \mathrm{ml}$ streptomycin (Sigma Co.), $20 \mathrm{mM}$ L-alanyl glutamine (Sigma Co.), $1 \times$ MEM nonessential amino acids (Sigma Co.) and 10\% (v/v) foetal calf serum (Biosera S1800; NWPLS; Heat Inactivated), supplemented with $10 \mathrm{ng} / \mathrm{ml}$ basic fibroblast growth factor (bFGF) (PeproTech, UK), and seeded on tissue culture treated Petri dishes at a density of 50,000-100,000 cells $/ \mathrm{cm}^{2}$. The dishes were incubated at $37^{\circ} \mathrm{C}$ in a humidified atmosphere of $5 \%$ $\mathrm{CO}_{2} / 95 \%$ air. The chondrocytes were allowed to expand until almost confluent, and then trypsinized and divide to other tissue culture treated Petri dishes using the same proportional relations.

\subsection{Chondrocyte culture on 3D SPCL fibre scaffolds}

Once the required cell number was achieved, confluent chondrocyte monolayers were harvested for seeding onto the polymeric scaffolds, as follows. The SPCL fibre scaffolds were allowed to equilibrate at room temperature in $10 \mathrm{ml}$ of expansion medium. The chondrocytes were removed from the culture dishes by trypsinisation. The chondrocytes were pelleted by centrifuging at $200 \mathrm{~g}$ for $7 \mathrm{~min}$ and the cell pellet ressuspended in expansion medium. The SPCL fibre scaffolds were placed on stainless steel wires in spinner flasks containing a suspension of chondrocytes with a concentration of $0.5 \times$ $10^{6}$ cells $/ \mathrm{ml}$ (4 scaffolds per spinner flask). The stirrer was 
set at a slow stirring of $75 \mathrm{rpm}$ and the spinner flasks left for $72 \mathrm{~h}$ to allow the cells to enter the scaffold material. After the seeding was completed, the chondrocytes/scaffold constructs were transferred to non-tissue culture treated sterile Petri dishes and $20 \mathrm{ml}$ of fresh expansion medium added to each Petri dish. The Petri dishes were placed on the orbital shaker, and set at a gentle shaking speed of $50 \mathrm{rpm}$. The constructs were left for 72-96 h to allow further expansion of the cells on the scaffolds. The expansion culture medium was then removed and replaced with $20 \mathrm{ml}$ of differentiation medium (Dulbecco's Modified Eagle's Medium (Sigma Co.), containing $10 \mathrm{mM}$ HEPES buffer pH 7.4 (Sigma Co.), 10000 units $/ \mathrm{ml}$ penicillin/10000 $\mu \mathrm{g} / \mathrm{ml}$ streptomycin(Sigma Co.), 20 mM L-alanyl glutamine (Sigma Co.), MEM nonessential amino acids (Sigma Co.), and 10\% (v/v) foetal calf serum (Biosera S1800; NWPLS; Heat Inactivated), supplemented with $1 \mu \mathrm{g} / \mathrm{ml}$ of insulin (Sigma Co.) and $50 \mu \mathrm{g} / \mathrm{ml}$ of L-ascorbic acid (Sigma Co.) to promote formation of a chondrogenic phenotype in the chondrocytes. The construct cultures were returned to the orbital shaker in the incubator and maintained at a speed of $50 \mathrm{rpm}$. The constructs were incubated until 42 days of culture, replacing the differentiation medium every $2-3$ days.

\subsection{Scanning electron microscopy}

The constructs were washed in sterile PBS and immersed in 3\% glutaraldehyde (Sigma Co.) with $0.1 \mathrm{M}$ cacodylate buffer $\mathrm{pH}$ 7.4) (AGAR) at room temperature for one hour. They were then washed three times in $0.1 \mathrm{M}$ cacodylate buffer $\mathrm{pH} 7.4$, and afterwards post fixed in $1 \%$ aqueous solution of osmium tetroxide (Fluka/Sigma Co.) for one hour. Finally, they were dehydrated in alcohols and let to dry. The samples were sputter coated with gold and observed using a Phillips XL-20 scanning electron microscope.

\subsection{Histological analysis (Hematoxylin-eosin, toluidine blue)}

Constructs were taken at specific culturing periods, until up to six weeks of total culturing time. The constructs were included in Optimal Cutting Temperature gel (OCT) (OCT compound $\mathrm{BDH}$, Gurr $\left.{ }^{\circledR}\right)$, frozen using liquid nitrogen and isopentane, stored at $-20^{\circ} \mathrm{C}$ for posterior cryosectioning. Tissue sections of $8 \mu \mathrm{m}$ were taken and fixed using fresh $4 \%$ paraformaldehyde (Sigma, Co.). The slides were then washed in distilled water, let to dry and stored at $4^{\circ} \mathrm{C}$ until the staining was performed. Hematoxylin-eosin stain was conducted in an automatic machine (Fume Cupboard; X219/E11/LEV1). In this procedure, the slides are stained in hematoxylin for a suitable time, optimised according to in-house procedures. The sections are washed in running tap water for $5 \mathrm{~min}$ or less, and afterwards differentiated in $1 \%$ acid alcohol, for 5-10 s.
The slides are washed again in tap water for 5 min or less, and stained in $1 \%$ eosin for $10 \mathrm{~min}$. They are again washed in tap water for $5 \mathrm{~min}$, and dehydrated through alcohols and mounted in DPX (Fluka/Sigma Co.). Toluidine blue staining was performed using standard histological methods in the following way. One drop of $1 \%$ toluidine blue was placed on each section for 2-3 s. The sections were rinsed with distilled water. Dehydration through alcohols followed and the sections were then left to dry overnight, and mounted in DPX.

\subsection{Immunolocalisation of collagen types I and II}

Collagen types I and II were detected immunohistochemically using monoclonal antibodies against collagen types I and II (Southern Biotechnology, UK), as previously described [25]. Briefly, fixed sections were washed with PBS and pre-treated with hyaluronidase $(10 \mathrm{mg} / \mathrm{ml})$ (Sigma Co.), followed by pronase $(2 \mathrm{mg} / \mathrm{ml})$ (Fluka/Sigma Co.). The slides were then washed thoroughly in PBS and treated with $3 \%$ hydrogen peroxide (Sigma Co.) in 50\% methanol (Aldrich), followed by washing in Tris-buffered saline (TBS) and blocking with 3\% bovine serum albumin (BSA) (Sigma Co.) Incubation with the primary antibody (collagen type I and collagen type II) (UNLB) followed. The remaining protocol is as described in the Vectastain Elite ABC Kit PK-6105 (Vector Laboratories Ltd., UK) and in the Vector DAB Kit (Vector Laboratories Ltd., UK). The slides were afterwards washed in water for $5 \mathrm{~min}$, counterstained with haematoxylin, and mounted with DPX mounting medium. Controls were performed using normal goat serum instead of the primary antibodies, which was included in the kit.

2.7 Dimethylmethylene blue (DMB) assay for glycosaminoglycans quantification

Proteoglycans were determined by measuring the level of sulphated glcosaminoglycans (GAGs) using the dimethylmethylene blue metachromatic assay as described previously [25]. GAG levels in solution can be quantified by binding of the acidic polymer to the basic dye, 1,9-dimethylmethylene blue (DMB). The resulting metachromatic shift peaks at $\mathrm{A}_{525-530}$ which can therefore be adapted for a spectrophotometric assay. Briefly, the constructs were immersed in a digestion solution with papain (Sigma Co.) and $\mathrm{N}$-acetyl cysteine (Sigma Co.), and incubated at $60^{\circ} \mathrm{C}$ overnight. After the digestion was completed, the tubes were centrifuged at $13,000 \mathrm{rpm}$ for $10 \mathrm{~min}$. The supernatant was collected and stored at $4^{\circ} \mathrm{C}$ until the GAG assay was performed. A chondroitin sulphate standard solution (Sigma Co.) was prepared in water and kept refrigerated. The samples and chondroitin sulphate standards were placed in a 96 well round-bottomed plate, DMB solution was added to each well, and the optical 
density measured using a microplate reader, at $530 \mathrm{~nm}$. Poly(glycolic acid) (PGA) non-woven scaffolds (Albany international, Bury, Lancashire, UK) were used as controls.

\section{Results and discussion}

\subsection{Scaffolds production}

A microcomputerized tomography $(\mu \mathrm{CT})$ image of a SPCL scaffold is shown in Fig. 1. It was observed that the fibre mesh network for support of cell growth and development presents good interconnectivity. The fibre network structure was advantageous for the dynamic seeding using spinner flasks. An extensive porous area (approximately $75 \%$ as estimated by $\mu \mathrm{CT}$ ) is an advantage towards cells penetration into the bulk of the scaffold, while also enhancing nutrients diffusion and removal of metabolic wastes. The scaffolds thickness $(3 \mathrm{~mm})$ is within the range of the values encountered for normal human articular cartilage [26].

\subsection{Scanning electron microscopy}

Scanning electron micrographs showed that the bovine articular chondrocytes extensively colonised the scaffold structure, being widely present at the surface and penetrating the various pores. We believe this is a consequence not only of the materials used, to which the cells adhere, but also to the scaffolds 3D arrangement, that in combination with the dynamic cells seeding using the spinner flasks, allowed the cells to spread and proliferate homogeneously throughout the entire construct. In fact, SPCL scaffolds have already been shown to be successful in bone tissue engineering approaches, in studies conducted with bone marrow stromal cells cultured in SPCL fibre based scaffolds, under dynamic conditions using bioreactors [27] The results presented here for the first time using SPCL scaffolds in a cartilage tissue engineering

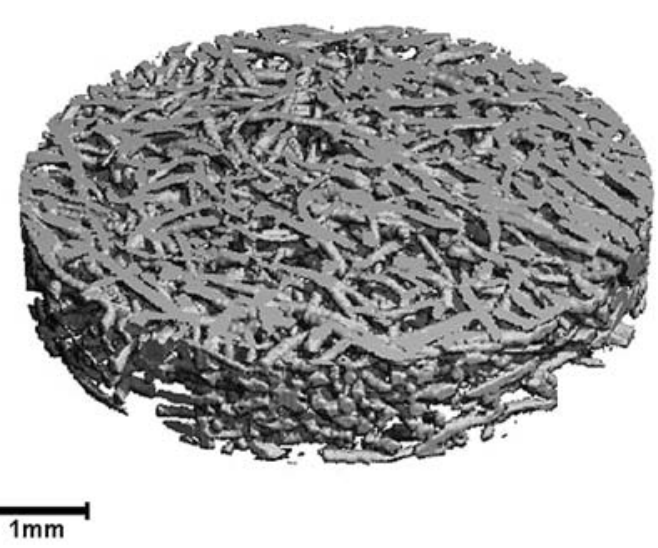

Fig. 1 Microcomputerized tomography image of a SPCL 30/70\% (wt) fibre scaffold approach constitute another evidence for the application of these supports in tissue engineering approaches.

Figures 2.1.A-C show at increasing magnifications, constructs collected after 2 weeks of culturing. Figure 2.1.A exhibits a global view over the cells-scaffold construct, showing that the cells were homogeneously distributed and had adhered uniformly, showing no difference between a fibre surface and the contact junction between two fibres. The morphology of the chondrocytes is the one of normal and healthy cells $[28,29]$, and these were forming multilayer as observed in Fig. 2.1.C. These observations indicate that with such an arrangement, the cells create a $3 \mathrm{D}$ environment which favours extracellular matrix formation.

Figures 2.2.A-C shows the cultured scaffolds at week 4. Comparison of Figs. 2.1.A and 2.2.A, corresponding to weeks 2 and 4 of culturing, respectively, showed higher cell coverage in the latter, indicating that the cells have proliferated during these periods. Comparing the results at week 4 (Figs. 2.2.A-C) with those from week 6 (Figs. 2.3.A-C), no difference is observed. However, it can be observed that the cell coverage was extensive in both time periods. These observations might be explained by the exchange in culture medium supply that was performed. The supply of expansion medium containing bFGF during the initial periods, induces cell proliferation which enables obtaining a full cell coverage on the scaffolds [30]. The change to a differentiation medium containing insulin and L-ascorbic acid (after 7 days of culture) would induce a decrease in the proliferation rates and trigger the onset of redifferentiation, with consequent expression of extracellular matrix [31].

\subsection{Hematoxylin-eosin and toluidine blue}

Figure 3 shows different histological sections of scaffolds taken at week 4 (Fig. 3.1.A.) and week 6 (Figs. 3.1.B-D). As shown previously in the SEM analysis, it can be observed an increase in cell mass from week 4 to week 6 , when comparing Figs. 3.1.A and B. Cells have also created a consistent adhesion interface with the SPCL fibres, as can be observed in Fig. 3.1.D (arrows). The histology processing usually leads the structures to contract, and the detachment of cell mass observed in some of the fibres is a result of that. The fact that continuity is observed at the cells-fibres interface allows us to predict the tissue engineered constructs may preserve its integrity in vivo, acting as one functional unit. It is also evident the cells presence in both bulk and more external areas of the scaffolds (Fig. 3(B)).

Regarding the PGA scaffolds, the observations indicate that these exhibited higher cell proliferation when compared to SPCL in the initial periods. We also detected a central area within the scaffolds were cells were lacking. Reasons for these occurrences may be related with inefficient cells penetration, necrosis due to high cell densities, or necrosis related 
2.1 .
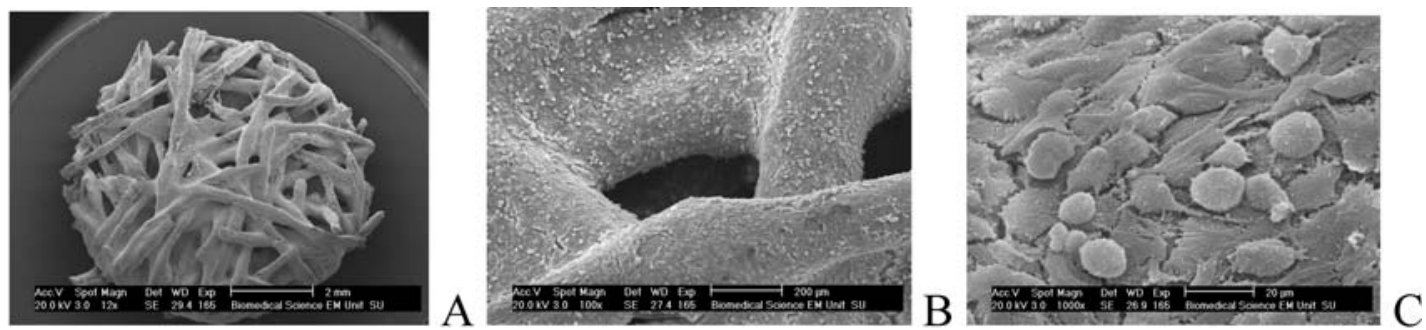

2.2 .
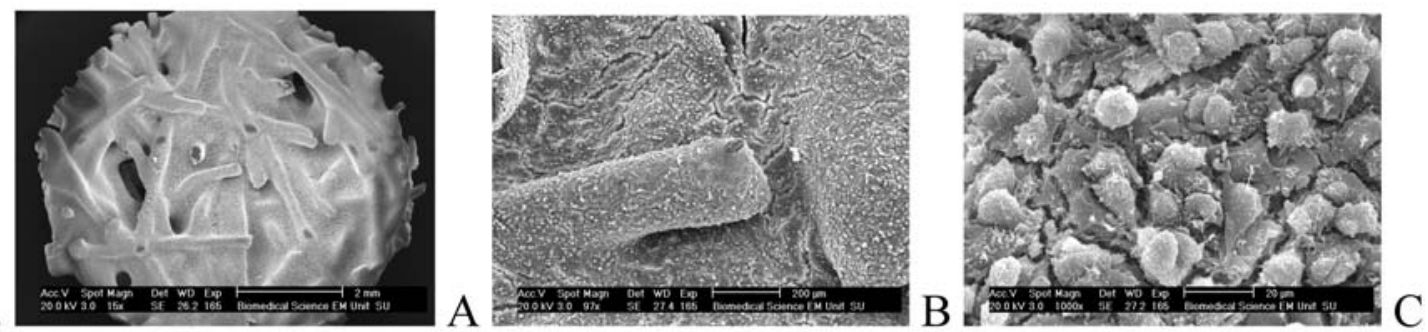

2.3 .
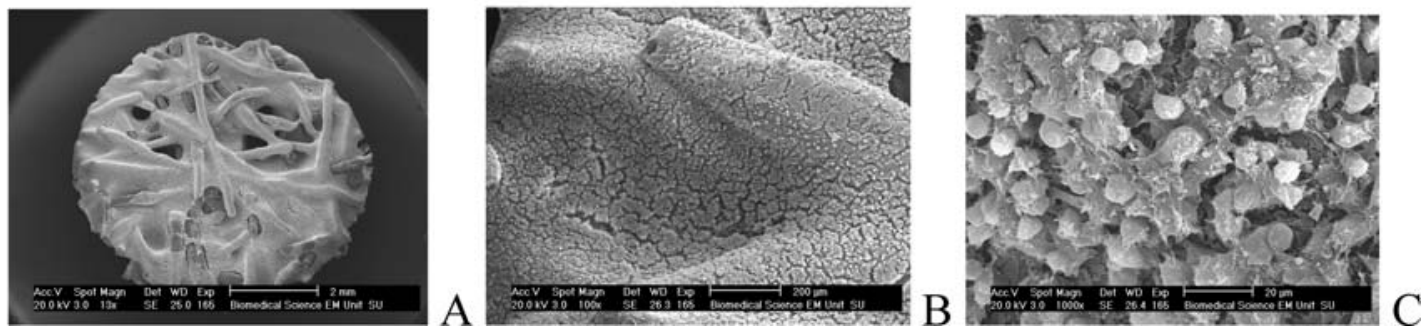

Fig. 2 Scanning electron microscopy images of SPCL scaffolds seeded with bovine articular chondrocytes and cultured for 14 days (2.1), 28 days (2.2), and 42 days (2.3). B and C represent higher magnifications of A, showing in detail the cells morphology and arrangement

3.1 .
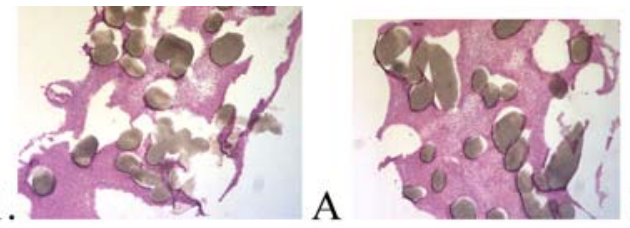

3.2 .

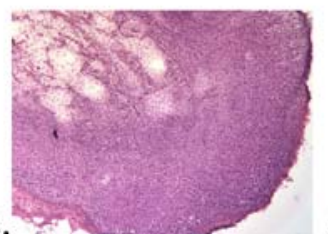

A

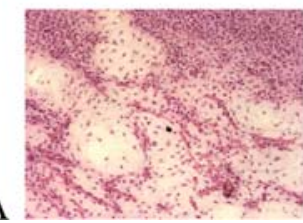

Fig. 3 Optical microscopy images of histology sections obtained from SPCL scaffolds seeded with bovine articular chondrocytes and stained with hematoxylin-eosin. The images shown correspond to samples collected after 28 days (3.1.A), and 42 days (3.1.B-D) of culture. Figures

with acidic by-products degradation, as shown in Figs. 3(E) and $(\mathrm{F})$. This was observed by week 4 of culture and correlates with data reported in the literature. PGA, as well as other polyesters, release acidic by-products in culture after a determined time period, as a result of hydrolytic chemical scission of the ester backbone [32]. PGA biodegradation occurs by non-specific hydrolytic scission of their ester bonds, resulting into glycolic acid residues that may substantially
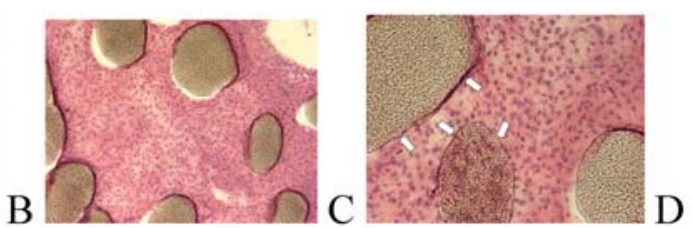

B

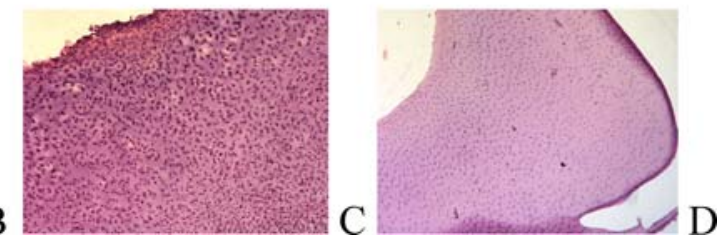

3.2.A-C show optical microscopy images of histology sections obtained from PGA scaffolds seeded with bovine articular chondrocytes and stained in the same way (42 days). Figure 3.2.D represents native bovine articular cartilage control stained using the same technique

decrease the solution $\mathrm{pH}$ and indirectly affect cell development [33].

Figures 4.1.A-D show toluidine blue stained histology sections of SPCL scaffolds seeded with bovine articular chondrocytes. Toluidine blue is a metachromatic stain that identifies glycosaminoglycans present in the extracellular matrix of hyaline cartilage. It is possible to observe a light purple staining at both time periods presented (Figs. 4.1.A- 
4.1 .

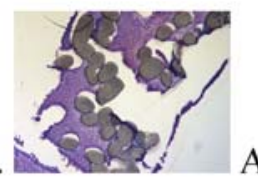

4.2 .
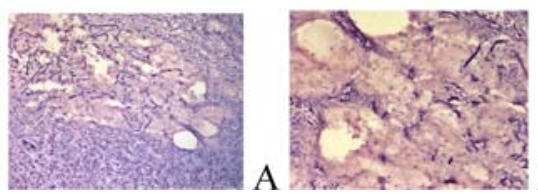

Fig. 4 Optical microscopy images of histology sections obtained from SPCL scaffolds seeded with bovine articular chondrocytes stained with toluidine blue. The images shown correspond to 28 days (4.1.A), and 42 days (4.1.B-D) of culturing. Optical microscopy images of histology

D), which indicates that the chondrocytes had produced an extracellular matrix containing proteoglycans. Proteoglycans enable cartilage to bind water molecules and account for the property of compressive stiffness important for the correct functioning of articular joints [25]. Therefore, the identification of glycosaminoglycans in the cell extracellular matrix is a positive indicator towards the formation of a cartilage-like tissue.

Concerning the PGA scaffolds, the results obtained from the staining with toluidine blue are very similar to those obtained for SPCL scaffolds. However, in PGA scaffolds no glycosaminoglycans presence was detected in the bulk area due to lack of cellular material (4.2.A-B), as previously mentioned in H\&E stained sections. Both tissue engineered constructs presented a staining profile very similar to the one encountered for native articular cartilage extracellular matrix (4.2.D).

\subsection{Immunolocalisation of collagen types I and II}

Four collagen types, namely, types II, IX, X, and XI, are traditionally considered specific for cartilage [34]. Collagen type II is the major protein produced by chondrocytes in articular cartilage, being involved in its weight bearing and adsorbing functions [35]. It was performed immunolocalisation of both collagen type I and collagen type II proteins in sections obtained from SPCL seeded scaffolds (Fig. 5.1.). The results correspond to samples collected at week 6 of culture. A difference in the expression pattern can be noted, when comparing collagen types I and II, with type II collagen displaying stronger antibody staining. When articular chondrocytes are isolated and expanded in 2D culture conditions, the cells expression profiles change. Collagen type II production is reduced and collagen type I is expressed. This process is described as dedifferentiation and it is a characteristic feature of chondrocytes grown in two dimensional cultures $[34,36]$. Once the cells reach confluence and begin to pack in multilayered 3D structures, they begin to re-
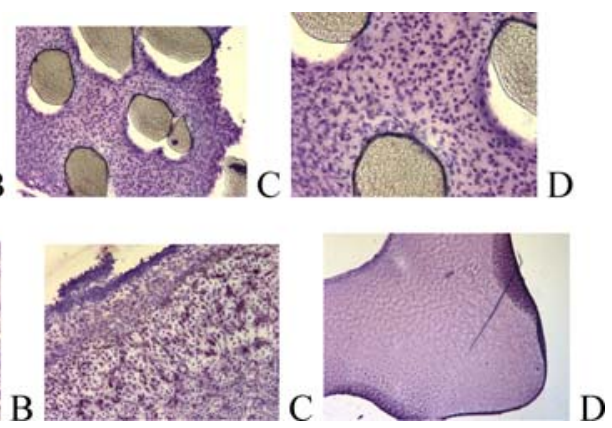

sections of PGA scaffolds seeded with bovine articular chondrocytes and stained with toluidine blue are presented at 42 days (4.2.A-C). Figure 4.2.D shows native bovine articular cartilage stained with toluidine blue dye

differentiate. Re-differentiation is the process of regaining normal articular cartilage molecules synthesis, such as collagen type II, aggregan, and Sox-9, for example [37, 38]. When in vitro differentiation is induced, type I collagen rapidly decreases during culture, and the levels of collagen type II and IX experience an increase [34, 35, 39]. Cell constructs studied herein presented stronger staining of collagen type II by week 4 (data not shown), which was maintained throughout the rest of the culture period. Collagen type II is the major structural macromolecule of hyaline cartilage, conferring tensile strength to the cartilage matrix and is thus a good marker of tissue engineered hyaline-like cartilage [25]. Considering this, the expression of these proteins, detected in the constructs cultured for 6 weeks, is another indication of the hyaline-like nature of these tissue engineered constructs.

Regarding the PGA scaffolds, it was observed a higher intensity staining with collagen type II antibodies than with collagen type I. Predominance of collagen type II staining over collagen type I in both types of scaffolds inferred that bovine articular chondrocytes regained a chondrogenic phenotype on the SPCL and PGA scaffolds. These results correlated with the toluidine blue staining, which reveal that glycosaminoglycans were present in the newly elaborated extracellular matrix.

\subsection{DMB assay for glycosaminoglycans quantification}

The glycosaminoglycans (GAG) were quantified using the dimethylmethylene blue (DMB) assay. Comparing the results obtained with SPCL constructs with the ones generated for PGA, it can be observed a wide difference in glycosaminoglycans quantification. Given the similar results obtained with the toluidine blue staining for both types of scaffolds, the higher values for GAGs concentration in PGA scaffolds may be a result of the apparently higher initial cell proliferation rates observed for the PGA scaffolds, when compared to SPCL. A higher cell number would result in an increase in the exrtracellular matrix components, as it is known that 
Fig. 5 Optical microscopy images presenting the results obtained from the immunolocalisation of collagen types I and II in histology sections of SPCL scaffolds seeded with bovine articular chondrocytes. Images present results at 42 days for collagen type I, collagen type II, and normal goat serum-control (left to right, respectively) (5.1.A-C; D-F). The images are shown at different magnifications. Below, comparative results are shown for PGA scaffolds at 42 days for collagen type I, collagen type II and normal goat serum-control (left to right, respectively) (5.2.A-C). Figure 5.3.A-C represents native bovine articular cartilage stained using the same method (collagen type I, collagen type II, and normal goat serum-control, from left to right, respectively)

Fig. 6 Results obtained from DMB assay for GAGs quantification results for SPCL and PGA scaffolds at different time periods
5.1.
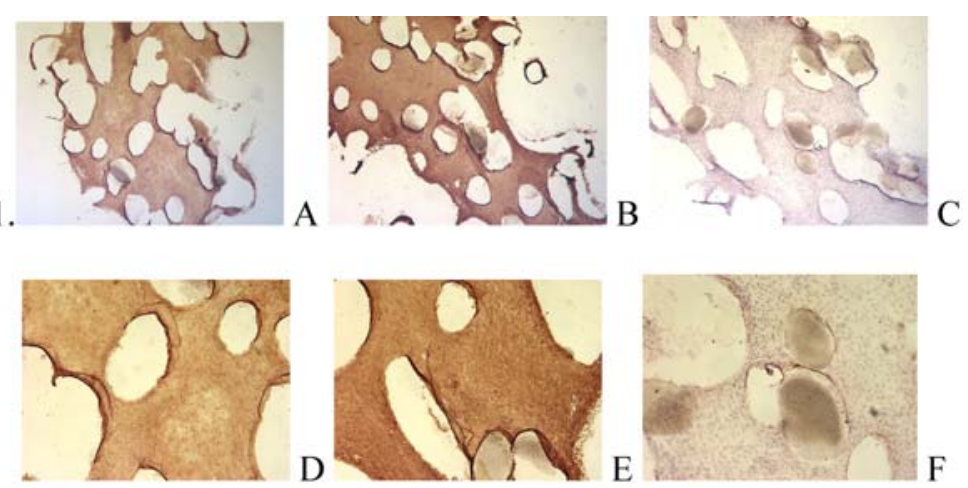

5.2 .
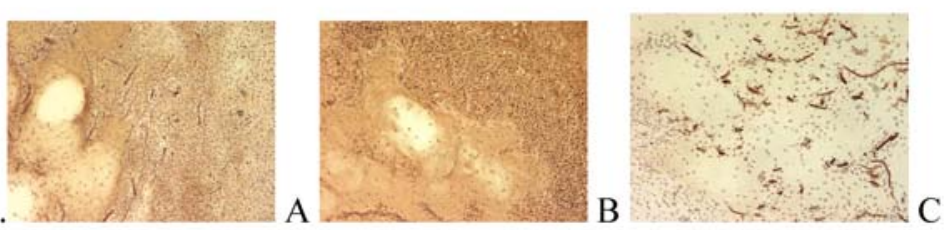

5.3
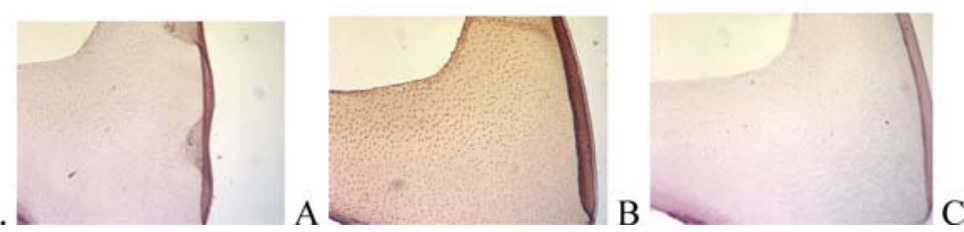

Mean GAG ug/ml undiluted sample

Mean GAG ug/ml undiluted sample

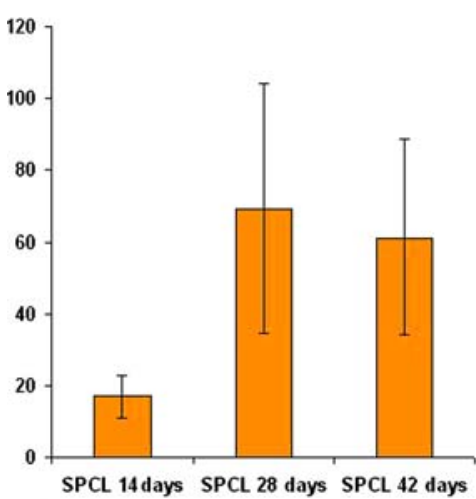

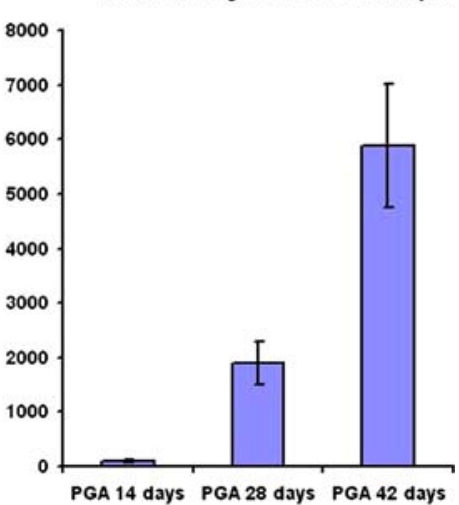

intercellular contacts exert extreme importance for chondrocytes to begin extracellular matrix deposition $[34,40]$. The fact that the cells were able to proliferate at higher rates in the PGA scaffolds may justify the higher glycosaminoglycans synthesis that was observed. However, this may be jeopardised by the tissue depletion observed in the central area of the PGA scaffolds, which can be a result of acidic by-products release, inefficient cells penetration or necrosis induced by high cellular densities that may lead to loss in mass transfer throughout the constructs. Furthermore, GAG deposition in SPCL may be achieved with some complementary strategies, such as the addition of certain growth factors. For example, it is described in the literature that bone morphogenetic protein 2 (BMP-2) and cartilage-derived morphogenetic protein 2 (CDMP-2) significantly enhance proteoglycans production on a chondrocytic cell line (MC615) [41]. Also, it has been shown that insulin-like growth factor type I (IGF-I) increases the synthesis of proteoglycans in bovine articular chondrocytes [31]. Some of these molecules can be added to the culture medium or even included in the scaffolds.

\section{Conclusions}

There is a great need for the development of clinically useful cartilage tissue engineering strategies. In this work, we have showed that SPCL scaffolds can support bovine articular chondrocytes adhesion, proliferation and differentiation, for up to 6 weeks of culturing. These scaffolds were compared with non-woven polyglycolic acid (PGA) scaffolds cultured using the same parameters. The PGA scaffolds presented a 
central area of cells depletion, which can be a result of acidic by-products release from their hydrolytic degradation, inefficient cells penetration or necrosis induced by high cellular densities. This can compromise the clinical application of these standard scaffolds. This situation was not observed in the SPCL scaffolds, which presented homogeneous cell colonization throughout the scaffold structure. The results obtained for toluidine blue staining and immunolocalisation of collagens types I and type II were very similar for both types of scaffold materials. Nevertheless, quantitatively, PGA scaffolds exhibited higher amounts of glycosaminoglycans, when compared to the SPCL scaffolds.

In summary, the results obtained from this work, demonstrate that the SPCL fibre based scaffolds may constitute a valid alternative and should be considered for further studies in the cartilage tissue engineering field, in addition to their already promising performance in the bone tissue engineering area.

Acknowledgments J.T. Oliveira would like to acknowledge the Portuguese Foundation for Science and Technology (FCT) for his grant (SFRH/BD17135/2004). The authors would like to thank Dr. Chris Hill for his help with the SEM analysis. This work was carried out under the scope of the European NoE EXPERTISSUES (NMP3-CT-2004500283).

\section{References}

1. A. J. SAlgADO, J. T. OlIVEIRA, A. J. PEDRO and R. L. REIS, Current Stem Cell Research \& Therapy 1 (2006) 231.

2. K. UEMATSU, K. HATTORI, Y. ISHIMOTO, J. YAMAUCHI, T. HABATA, Y. TAKAKURA, H. OHGUSHI, T. FUKUCHI and M. SATO, Biomaterials 26(20) (2005) 4273.

3. R. CANCEDDA, B. DOZIN, P. GIANNONI and R. QUARTO, Matrix. Biol. 22(1) (2003) 81.

4. G. CHEN, D. LIU, M. TADOKORO, R. HIROCHIKA, H. OHGUSHI, J. TANAKA and T. TATEISHI, Biochem. Biophys. Res. Commun. 322(1) (2004) 50.

5. J. S. TEMENOFF and A. G. MIKOS, Biomaterials 21(5) (2000) 431.

6. A. J. GRODZINS K Y, Crit. Rev. Biomed. Eng. 9(2) (1983) 133.

7. W. ZHU, V. C. MOW, T. J. KOOB and D. R. EYRE, J. Orthop. Res. 11(6) (1993) 771.

8. M. B. YAYLAOGLU, C. YILDIZ, F. KORKUSUZ and V. H A S IR C I, Biomaterials 20(16) (1999) 1513.

9. C. R. LEE, H. A. BREINAN, S. NEHRER and M. SPECTOR, Tissue Eng. 6(5) (2000) 555.

10. Z. GUGALA and S. GOGOLEWSKI, J. Biomed. Mate. Res. 49(2) (2000) 183.

11. P. GIANNONI, A. PAGANO, E. MAGGi, R. ARBICO, N. RANDAZZO, M. GRANDIZIO, R. CANCEDDA and B. DOZIN, Osteoarthritis and Cartilage 13(7) (2005) 589.

12. Z. GUGALA and S. GOGOLEWS KI, J. Biomed. Mater. Res. 49(2) (2000) 183.

13. D. W. HUTMACHER, Biomaterials 21(24) (2000) 2529.

14. J. - A. HAN and S . - T . LIM, Carbohydrate Polymers 55(3) (2004) 265.

15. T. FUNAMI, Y. KATAOKA, T. OMOTO, Y. GOTO, I. A S AI and K. NIS HIN A R I, Food Hydrocolloids 19(1) (2005) 25.
16. A. P. MARQUES, R. L. REIS and J. A. HUNT, Macromol. Biosci. 5(8) (2005) 775.

17. M. E. GOMES, J. S. GODINHO, D. TCHALAMOV, A. M. CUNHA and R. L. REIS, Mater. Sci. Eng.: C 20(1/2) (2002) 19.

18. A. J. SALGADO, O. P. COUTINHO and R. L. REIS, Tissue Eng. 10(3) (2004) 465.

19. A. P. MARQUES and R. L. REIS, Mater. Sci. Eng. CBiomimetic and Supramolecular Syst. 25(2) (2005) 215.

20. W. J. LI, K. G. DANIELSON, P. G. ALEXANDER and R. S. TUAN, J. Biomed. Mater. Res. - Part A 67(4) (2003) 1105.

21. W.-J. LI, R. TULI, C. OKAFOR, A. DERFOUL, K. G. DANIELSON, D. J. HALL and R. S. TUAN, Biomaterials 26(6) (2005) 599.

22. M. E. GOMES, V. I. SIKAVITSAS, E. BEHRAVESH, R. L. REIS and A. G. MIKOS, J. Biomed. Mater. Res. A. 67(1) (2003) 87.

23. A. J. SALGADO, O. P. COUTINHO and R. L. REIS, Tissue Eng. 10(3) (2004) 465.

24. A. CR A WFOR D and S . C. DICKIN S ON, "Methods in Molecular Biology: Biopolymer Methods in Tissue Engineering" (Humana Press Inc., US, Totowa, NJ, 2004).

25. W. KAFIENAH and T.J. SIMS, "Methods in Molecular Biology: Biopolymer Methods in Tissue Engineering (Humana Press Inc., US, Totowa, NJ, 2004).

26. A. THAMBYAH, A. NATHER and J. GOH, Osteoarthritis and Cartilage In Press, Corrected Proof.

27. M. E. GOMES, V. I. SIKAVITSAS, E. BEHRAVESH, R. L. REIS and A. G. MIK OS, J. Biomed. Mater.Res. Part A 67A(1) (2003) 87.

28. J. J. A. BARRY, H. S. GIDDA, C. A. SCOTCHFORD and S. M. HOW DLE, Biomaterials 25(17) (2004) 3559.

29. V. J. D. CIOLFi, R. PILliaR, C. MCCULlOCH, S. X. WANG, M. D. GRYNPAS and R. A. KANDEL, Biomaterials 24(26) (2003) 4761.

30. P. CUEVAS, J. BURGOS and A. BAIRD, Biochem. Biophy. Rese. Commun. 156(2) (1988) 611.

31. F. P. LUYTEN, V. C. HASCALL, S. P. NISSLEY, T. I. MOR ALES and A. H. REDDI, Arch. Biochem. Biophys. 267(2) (1988) 416.

32. A. W. T. SHUM and A. F. T. MAK, Polymer Degradation and Stability 81(1) (2003) 141.

33. K. A. AthanAsiou, C. M. AgRAWAL, F. A. B ARBER and S. S. BURKHART, Arthroscopy: The Journal Arthroscopic \& Related Surgery 14(7) (1998) 726.

34. R. CANCEDDA, F. DESCALZI CANCEDDA and P. CAST A GNOLA, Int. Rev. Cytol. 159 (1995) 265.

35. K. R. BRODKIN, A. J. GARCIA and M. E. LEVENSTON, Biomaterials 25(28) (2004) 5929.

36. E. M. DARLING and K. A. ATHANASIOU, Ann. Biomed. Eng. 31(9) (2003) 1114.

37. B. DOZIN, M. MALPELI, L. CAMARDELLA, R. CANCEDDA and A. PIETRANGELO, Matrix Biol. 21(5) (2002) 449.

38. R. S. TARE, D. HOWARD, J. C. POUND, H. I. ROACH and R. O. C. OREFFO, Biochem. Biophys. Res. Commun. 333(2) (2005) 609.

39. C. KAPS, S. FRAUENSCHUH, M. ENDRES, J. RINGE, A. HAISCH, J. LAUBER, J. BUER, V. KRENN, T. HAUPL, G.-R. BURMESTER and M. SITTINGER, Biomaterials 27(19) (2006) 3617.

40. S. LOTY, C. FOLL, N. FOREST and J.-M. SAUTIER, Archives of Oral Biology 45(10) (2000) 843.

41. J. LI, K. S. KIM, J. S. PARK, W. A. ELMER, W. C. HUTtON and S. T. Y OON, J. Orthopaedic Sci 8(6) (2003) 829. 